\title{
TYPHOID ILEAL PERFORATION: A RETROSPECTIVE STUDY
}

Sagar Zarappa1, Lakkanna Suggaiah², Satyanarayan Vamangiri3, Usharani4, Shankarappa5, Preetham Raj6, Rajesh Cheluvarangaiah Krishnarajesh7, Bharath Basavraju ${ }^{8}$

1 Post Graduate, Department of General Surgery, ESIC PGIMSR, Rajajinagar, Bangalore.

2 Professor and HOD, Department of General Surgery, ESIC PGIMSR, Rajajinagar, Bangalore.

${ }^{3}$ Associate Professor, Department of General Surgery, ESIC PGIMSR, Rajajinagar, Bangalore.

${ }^{4}$ Senior Specialist, Department of General Surgery, ESIC PGIMSR, Rajajinagar, Bangalore.

${ }^{5}$ Senior Specialist, Department of General Surgery, ESIC PGIMSR, Rajajinagar, Bangalore.

${ }^{6}$ Assistant Professor, Department of General Surgery, ESIC PGIMSR, Rajajinagar, Bangalore.

${ }^{7}$ Post Graduate, Department of General Surgery, ESIC PGIMSR, Rajajinagar, Bangalore.

${ }^{8}$ Post Graduate, Department of General Surgery, ESIC PGIMSR, Rajajinagar, Bangalore.

\section{ABSTRACT}

\section{AIMS AND OBJECTIVES}

To determine the prognostic factor for mortality and to review our experience on the various surgical methods in the management of typhoid ileal perforation.

\section{METHOD OF STUDY}

A retrospective study of 30 patients from July 2014 to July 2015 in our hospital.

\section{RESULTS}

The duration of symptoms ranged from 4 to 21 days. Age (12-48)yrs. M:F ratio was 3:2, patient was operated within $48 \mathrm{hrs}$. Single perforation: multiple perforation is 25:5; 15 patients underwent simple closure of perforation, 10 patients ileostomy and 5 patients resection anastomosis. Wound infection was the most common complication. Overall mortality was $3 \%$ in our study.

\section{CONCLUSION}

Surgery is the definitive mode of treatment and early intervention, appropriate surgical methods, antibiotics, perioperative care reduces morbidity and mortality.

\section{KEYWORDS}

Typhoid, Perforation, Ileostomy, Primary Closure, Resection Anastomosis.

HOW TO CITE THIS ARTICLE: Zarappa S, Suggaiah L, Vamangiri S, et al. Typhoid ileal perforation-a retrospective study. J Evolution Med Dent Sci 2016;5(3):229-232, DOI: 10.14260/jemds/2016/49

\section{INTRODUCTION}

Typhoid fever is an infectious disease caused by the bacteria Salmonella typhi. It is clinically characterised by fever, pain abdomen, vomiting, constipation.(1,2) it may cause ulceration, hemorrhage, perforation secondary to local GI lesion.(2)

It is more common in developing countries due to, rapid population growth, limited water supply, poor socio-economic status, overburdened health care system, increasing antibiotic resistance among S. typhi.

Ileal perforation occurs in 1-5\% cases of typhoid fever. Immediate Surgery is accepted as definite treatment. Various operative procedures are. $(3,4,5)$

- Simple closure of the perforation.

- Resection and anastomosis.

- Ileostomy.

Postoperative complications of typhoid ileal perforation includes. ${ }^{6,7,8)}$ wound infection, wound dehiscence, fecal fistula,

Financial or Other, Competing Interest: None.

Submission 13-12-2015, Peer Review 17-12-2015,

Acceptance 06-01-2016, Published 11-01-2016.

Corresponding Author:

Dr. Sagar Zarappa,

\#65, Sagar Nilaya, Vinayaka Nagar,

Heserghatta,

Bangalore.

E-mail: sagarzbmc4@gmail.com

DOI:10.14260/jemds/2016/49 peritonitis, septicemia, ileostomy related complications, intestinal obstruction. Of all the postoperative complications fecal fistula is associated with significant morbidity and mortality. ${ }^{9}$

\section{AIMS AND OBJECTIVES}

To review our experience on the various surgical methods in the management of typhoid ileal perforation and to determine the prognostic factor for mortality in our setting.

\section{MATERIALS AND METHODS}

The study was done in: Dept. of Gen Surgery, ESICMC PGIMSR, Rajajinagar, Bengaluru. It is a retrospective study of 30 patients admitted with typhoid ileal perforation from Aug 2013 to Aug 2014.

\section{Inclusion Criteria}

Cases of peritonitis with typhoid ileal perforation were included in the study.

\section{Exclusion Criteria}

Peritonitis due to other ileal perforations, duodenal, gastric, traumatic perforations and Patients with previous abdominal surgeries were excluded from the study. 


\section{Preoperative Preparation}

Preoperative Investigations such as routine biochemical investigation, Chest and abdominal radiographs to detect air under diaphragm, Blood culture, Widal test were done.

Preoperative resuscitation includes, intravenous IV fluids, electrolyte derangement correction and commencement of antibiotics (Ceftriaxone, metronidazole and Amikacin), Diagnosis was further supported by operative finding of ileal perforation associated with peritoneal soilage.

The operative procedure was determined by the general condition of the patient, number of perforations \& degree of peritoneal contamination. Exploratory laparotomy done with midline incision,

Twenty six pts. were operated within $24 \mathrm{hrs}$, 4 pts were operated in next $24 \mathrm{hrs}$, the delay being caused by the need for adequate resuscitation. Operative findings were noted. Number of perforation, amount of pus and fecal matter were estimated; edge of ileal perforation were excised and sent for histopathology and closed transversely in two layers with 2-0 vicryl. Peritoneal cavity was irrigated with copious amount of normal saline. Drains were inserted to drain right paracolic gutter and pelvic cavity. Drains were brought out $10 \mathrm{cms}$ away from the main wound. Abdomen closed in layers. Discharged patients were followed up for 3-4 months.

Data Collected were Analysed using SPSS Software Version 21.0

\section{RESULTS}

\section{Duration of Symptoms}

Fever and pain abdomen was the most common symptoms, followed by vomiting, constipation and diarrhea. (Fig 1).

Duration of symptoms ranged from 4 to 21 days (Mean 15.4 days)

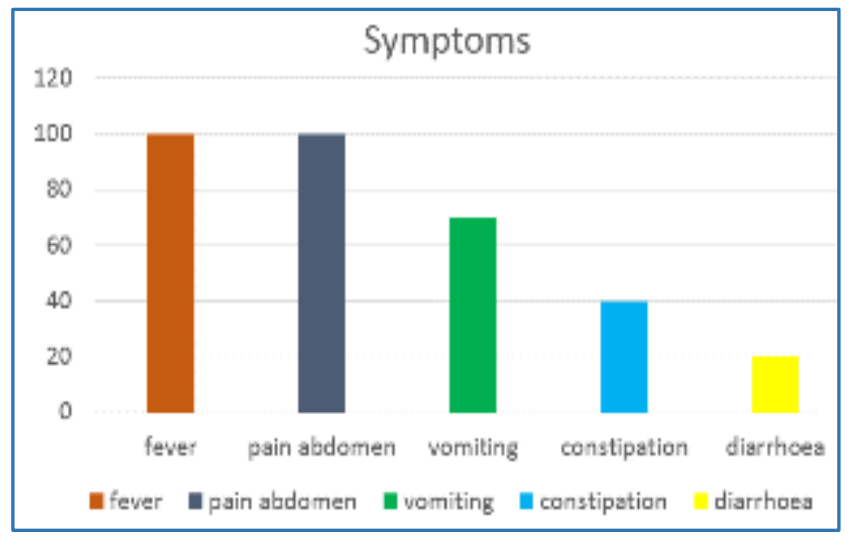

Fig. 1

\section{Age Distribution}

In our study it was more common in $4^{\text {th }}$ decade, that is between 31-40 yrs. age limit in our study was 11-50 years. Minimum age patient was $12 \mathrm{yrs}$. and maximum age patient was $48 \mathrm{yrs}$. (Fig. 2).

Min- 12 yrs.

Max- 48 yrs.

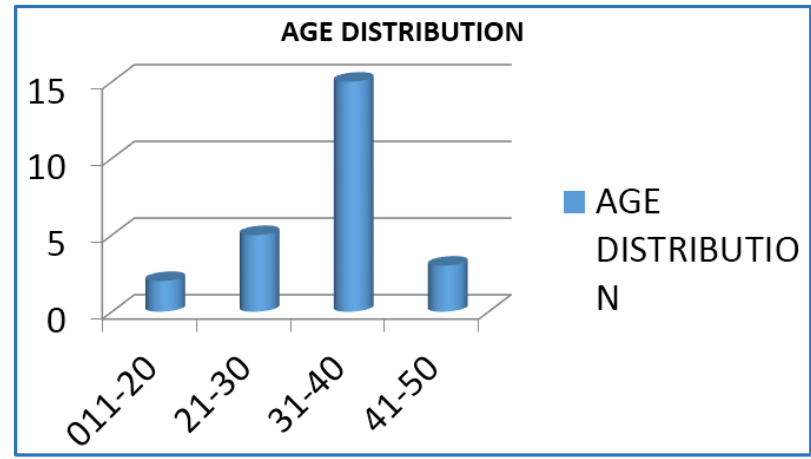

Fig. 2

\section{Sex Distribution}

It was more common in males compared to females in the ratio of 3:2; 18 patients were male and 12 patients were females. (Fig. 3) M:F 3:2.

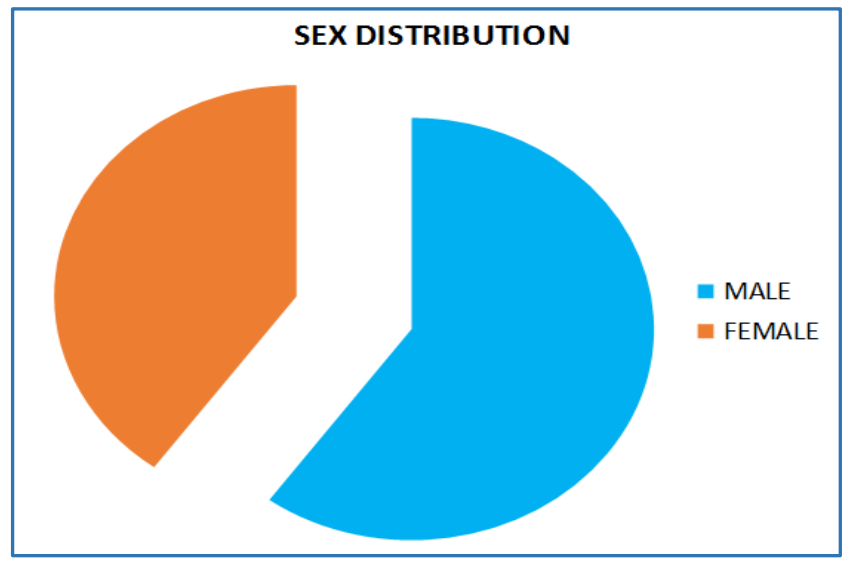

Fig. 3

\section{Investigations}

All patients underwent routine blood and radiological investigations and some specific investigations such as Widal test, blood culture and urine culture; 24 patients were Widal test positive, 8 patients were blood and urine culture positive; 22 patients had air under diaphragm on erect X-ray abdomen. (Fig. 4).

\begin{tabular}{|l|}
\hline HAEMOGLOBIN. \\
\hline TOTAL COUNT, DIFFERENTIAL COUNT. \\
\hline ERYTHROCYTE SEDIMENTATION RATE. \\
\hline PACKED CELL VOLUME. \\
\hline SERUM ELECTOLYTES. \\
\hline BLOOD UREA. \\
\hline SERUM CREATININE. \\
\hline BLOOD SUGAR-2 PATIENTS WERE DIABETICS. \\
\hline WIDAL TEST (+80\%). \\
\hline BLOOD CULTURE (+25\%). \\
\hline URINE CULTURE (+25\%). \\
\hline CHEST AND ERECT X -RAY ABDOMEN (72\%). \\
\hline ULTRASOUND ABDOMEN. \\
\hline \multicolumn{1}{|c|}{ Fig. 4: Invesitgations } \\
\hline
\end{tabular}

\section{Number of Perforations}

In 30 patients who underwent laparotomy for typhoid ileal perforations, 25 patients had single perforations and 5 patients had more than 1 perforation on intraop. (Fig. 5). 


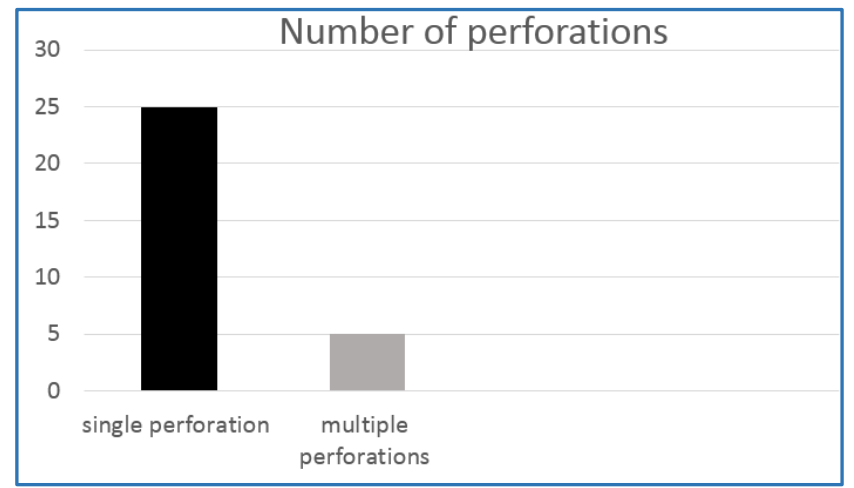

Fig. 5

\section{Extent of Contamination}

Amount of pus and fecal matter drained from the peritoneal cavity reflected the extent of contamination. 250-1000 ml was noted in 29 patients and $>1000 \mathrm{ml}$ in 1 patient $(100 \%$ mortality) (Fig. 6).

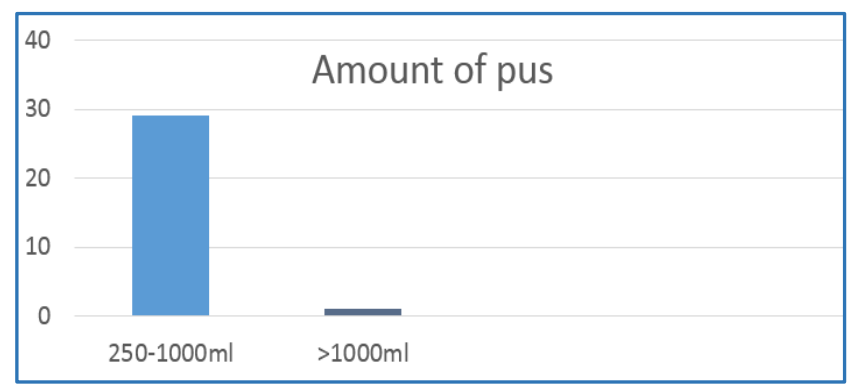

\section{Surgical Procedure}

Fig. 6

Among 30 patients 15 patients underwent primary closure, 10 patients underwent ileostomy and 5 patients underwent resection anastomosis. The operative procedure was determined by the general condition of the patient, number of perforations and degree of peritoneal contamination. Exploratory laparotomy done with midline incision. (Fig 7).

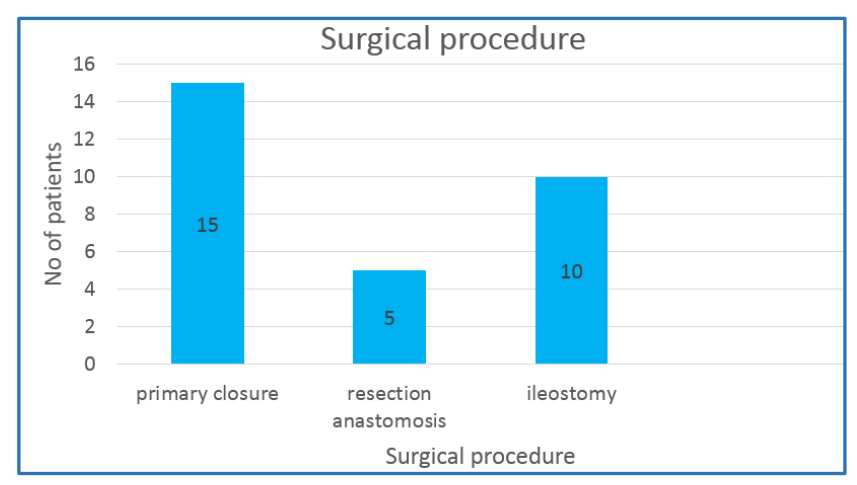

Fig. 7

\section{COMPLICATIONS}

Wound infection was the most common complications seen in all the three procedures. Two patients developed fecal fistula who underwent resection anastomosis, 1 patient was managed conservatively and other patient died due to septicemia. Ileostomy related complications such as prolapse, skin excoriation, retraction was seen in ileostomy patients which was managed conservatively. Overall, mortality in our study was $-3 \%$. (Fig. 8).

\section{COMPLICATIONS}

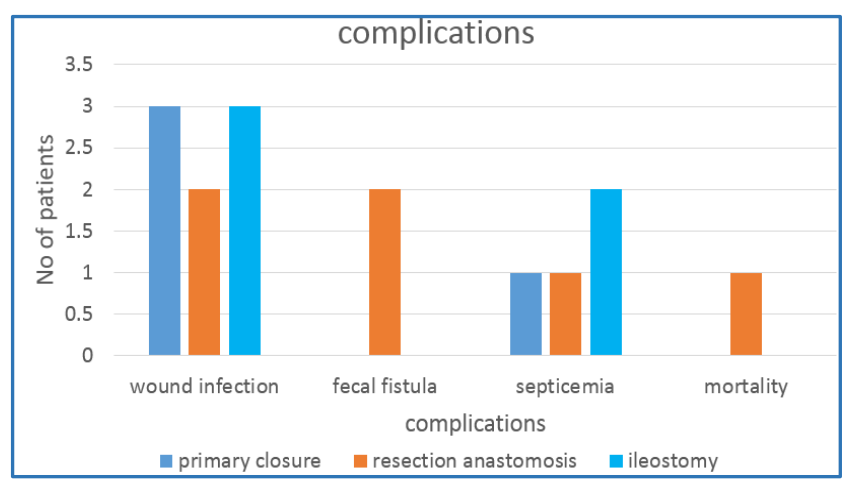

Fig. 8

\section{Histopathology}

Histopathology showing infiltration of tissues by macrophages (Typhoid cells) that contains bacteria, erythrocytes and degenerated lymphocytes. (Fig. 9).

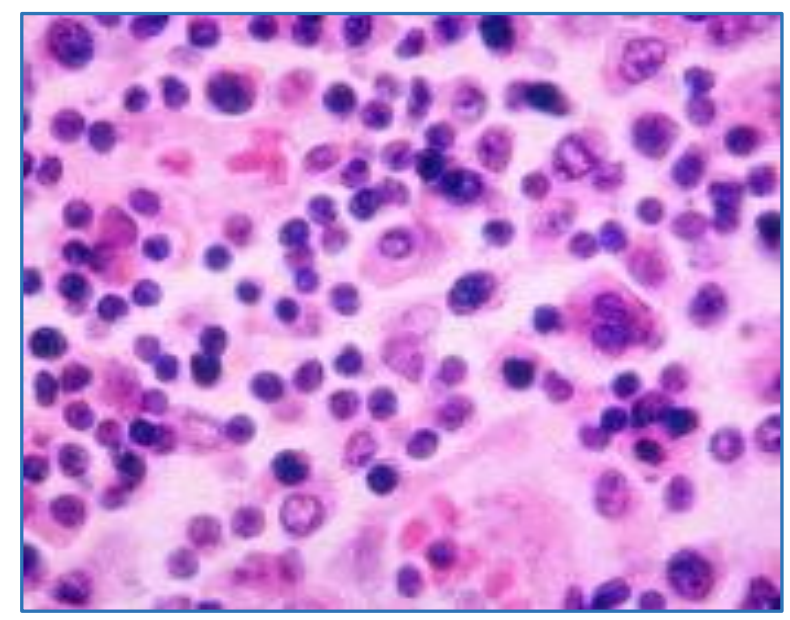

\section{DISCUSSION}

Fig. 9

Ileal perforations are most commonly observed in third and fourth decade of life.(1,2) More common in males compared to females (3:2).(2,3) Fever and pain abdomen was the most common clinical presentation followed by signs of peritonitis. $(2,10,11)$ Late presentation and delay in operation were associated with high mortality and high incidence of fecal fistula. $(4,12)$

Presence of solitary perforation and moderate peritoneal contamination produced favorable results, presence of multiple perforation and severe peritoneal contamination associated with development of complications such as wound infection, wound dehiscence, residual intra-abdominal abscess and fecal fistula.

Fecal fistula was the most dreaded and fatal complication, and was found to be commonest in patients where resection anastomosis was done. In patients who underwent ileostomy, 2 patients developed skin excoriations due to fecal spillage; 1 patients developed prolapse, 1 patient developed retraction. $(9,13,14)$

\section{Postoperative Death were due to,}

- Late presentation.

- Multiple perforation.

- Severe peritoneal contamination.

- Septicemia. 


\section{CONCLUSION}

It is universally accepted that the treatment for typhoid perforation must be surgical, essential for successful outcome. Early recognition, appropriate surgical intervention and antibiotics, effective perioperative care reduces the mortality in typhoid ileal perforation. Old age, immune suppression, delayed presentation, multiple perforation, severe peritoneal contamination are important predictors of mortality. Primary closure of the perforation is a preferred technique in clinically stable patients with a single perforation with minimal contamination of the abdominal cavity. Ileostomy should be preferred in patients with more than one perforation with massive fecal contamination of the abdominal cavity. Resection anastomosis is ideal in multiple perforation with minimal peritoneal contamination.

\section{Comparison with Other Studies (Table 2)}

\begin{tabular}{|c|c|c|c|c|}
\hline COMPLICATIONS & $\begin{array}{c}\text { STUDY } \\
(\mathrm{n}=30 \mathrm{pts})\end{array}$ & $\begin{array}{c}\text { Anupama Pujar et al. } \\
(n=40)\end{array}$ & $\begin{array}{c}\text { Sushil Mittal et al. } \\
(n=60)\end{array}$ & $\begin{array}{l}\text { Arshad et al. } \\
(n=112)\end{array}$ \\
\hline Wound infection & $8(26 \%)$ & $17(42 \%)$ & $24(40 \%)$ & $14(12 \%)$ \\
\hline Fecal fistula & $2(6 \%)$ & $3(7 \%)$ & $6(10 \%)$ & $10(8 \%)$ \\
\hline Sepsis & $4(13 \%)$ & $3(7 \%)$ & $5(8 \%)$ & $4(3 \%)$ \\
\hline Ileostomy related complications & $4(6 \%)$ & $2(5 \%)$ & $6(10 \%)$ & $5(4 \%)$ \\
\hline Mortality & $1(3 \%)$ & $2(5 \%)$ & $5(8 \%)$ & $8(7 \%)$ \\
\hline
\end{tabular}

\section{Emphasis must be on preventive measures.}

- Safe drinking water,

- Proper sewage disposal,

- Typhoid vaccination.

\section{REFERENCES}

1. Wani RA, Parray FQ, Bhat NA, Wani MA, Bhat TH and Farzana F, 2006. "Non-traumatic terminal ileal perforation," World Journal of Emergency Surgery, vol. 24 , no. 1 , article 7 .

2. Adesunkanmi RK, Badmus TA, Fadiora FO, et al. 2005. "Generalized peritonitis secondary to typhoid ileal perforation: assessment of severity using modified APACHE II score," Indian Journal of Surgery, vol. 67, no. 1, pp. 29-33.

3. Sushil Mittal, Harnam Singh, Anand Munghate, Gurpreet Singh, Anjna Garg and Jyoti Sharma, 2014. "A comparative study between the outcome of primary repair versus loop ileostomy in ileal perforation." Surgery Research and Practice, vol. 2014, Article ID 729018, 4 pages, 2014. doi:10.1155/2014/729018.

4. Meh EA and Dogo P, 1997. Comparison of three operations for typhoid perforation, BJS. 84:558.

5. Bouzidi A and Fares F, 1984. Role of ileostomy in typhoid peritonitis. J Chir (Paris), 121:359-363.
6. Kouame J, Kou Adio L and Turquin HT, 2004. Typhoid ileal perforation: surgical experience of 64 prospective study of 46 cases. Acta Chir Belg. 104:445-447.

7. Athie CG and Guizar CB et al., 1998. Twenty five years of experience in the surgical treatment of perforation of ileum caused by salmonella typhi at the General Hospital of Mexico City. Surgery, 23:632-636.

8. Singh KP and Singh K et al., 1991. Choice of surgical procedure in typhoid perforation. Experience in 42 cases. J Indian Med Assoc. 89:255-256.

9. Arshad et al. 2006. Different surgical options and ileostomy in typhoid perforation. World Journal of Medical Sciences, 112-116.

10. Rehman A, 2003. Spontaneous ileal perforation: an experience of 33 cases. J Post Grad Med Inst. 17:105-110.

11. Waqar A and Aslam M, et al. 2002. Clinical spectrum of typhoid fever in children in a descriptive 1995. Typhoid enteric perforation. Br J Surg 82: study at Sheikh Zaid Hospital Lahore. Pakistan Ped, 1512-1515. J, 26:71-75.

12. Ajao OG, 1982. Typhoid perforation, factors affecting morbidity and mortality. Int Surg, 67:317-319.

13. Khalid S and Irfan A, et al. 2000. Outcome of ileostomy in cases of typhoid perforation presenting after 48 hours. J Rawal Med Coll, 4:17-19.

14. Kaul BK, 1975. Operative management of typhoid perforation in children. Int Surg, 60:407. 